Article

\title{
Introducing the Shared Micro-Depot Network for Last-Mile Logistics
}

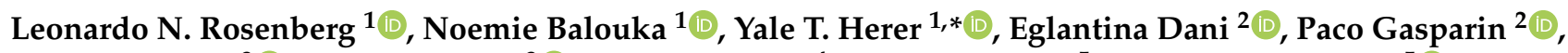 \\ Kerstin Dobers ${ }^{3} \mathbb{D}$, David Rüdiger ${ }^{3}{ }^{\mathbb{D}}$, Pete Pättiniemi ${ }^{4}$, Peter Portheine ${ }^{5}$ and Sonja van Uden ${ }^{5} \mathbb{B}$ \\ 1 Faculty of Industrial Engineering and Management, Technion-Israel Institute of Technology, Technion City, \\ 3200003 Haifa, Israel; leonardo@campus.technion.ac.il (L.N.R.); nbalouka@campus.technion.ac.il (N.B.) \\ 2 CIMNE-International Centre for Numerical Methods in Engineering, Edifici C1 Campus Nord UPC C/Gran \\ Capità, 08034 Barcelona, Spain; eglantina.dani@upc.edu (E.D.); francesc.gasparin@upc.edu (P.G.) \\ 3 Fraunhofer Institute for Material Flow and Logistics IML, 44227 Dortmund, Germany; \\ Kerstin.Dobers@iml.fraunhofer.de (K.D.); ruediger@mobildus.de (D.R.) \\ 4 Forum Virum Helsinki, FI00130 Helsinki, Finland; pete.pattiniemi@forumvirium.fi \\ 5 Brainport Smart District, 5708 JZ Helmond, The Netherlands; p.portheine@brainportsmartdistrict.nl (P.P.); \\ sonja@thepeoplefactor.nl (S.v.U.) \\ * Correspondence: yale@technion.ac.il
}

check for updates

Citation: Rosenberg, L.N.; Balouka, N.; Herer, Y.T.; Dani, E.; Gasparin, P.; Dobers, K.; Rüdiger, D.; Pete Pättiniemi, P.; Portheine, P.; van Uden, $\mathrm{S}$. Introducing the Shared Micro-Depot Network for Last-Mile Logistics. Sustainability 2021, 13, 2067 https:/ / doi.org/10.3390/su13042067

Academic Editor: Guido Perboli Received: 29 December 2020 Accepted: 10 February 2021 Published: 15 February 2021

Publisher's Note: MDPI stays neutral with regard to jurisdictional clai$\mathrm{ms}$ in published maps and institutional affiliations.

Copyright: () 2021 by the authors. Licensee MDPI, Basel, Switzerland. This article is an open access article distributed under the terms and conditions of the Creative Commons Attribution (CC BY) license (https:// creativecommons.org/licenses/by/ $4.0 /)$.
Abstract: Last-mile logistics is both a source and cause of problems in urban areas, especially problems related to traffic congestion, unsustainable delivery modes, and limited parking availability. In this context, multiple sustainable logistics solutions have been proposed. We focus on microdepots (MDs), which can function as a consolidation center and a collection-and-delivery point for business-to-consumer (B2C) small parcels. This paper presents a new research idea that extends the existing MD solution by introducing the concept of a shared MD network with parcel lockers. Such networks enable multiple logistics service providers (LSPs) and/or business partners to use an MD while minimizing their individual costs and optimizing the use of urban space. We present case studies of such shared MD networks operating in the cities of Helsinki and Helmond. We provide a framework for auxiliary businesses that can exploit the existing MD structure to offer services to the surrounding population. Finally, we define metrics for evaluating the success of shared MD networks while considering social, environmental and economic objectives. The case studies highlight the complexity of implementing such a solution; it requires stakeholders' involvement and collaboration. In particular, deciding on the location for a shared MD network is a critical phase, since local authorities have their own regulations, and residents' preferences are usually different than LSPs' ones. Nevertheless, if these challenges are overcome, this sustainable last-mile logistics solution has a promising future.

Keywords: last-mile logistics; sustainable last-mile delivery; urban logistics; micro-depot; city logistics; smart city; parcel lockers; collection-and-delivery points; shared facilities

\section{Introduction}

Last-mile logistics focuses on delivering parcels to the end-customers' preferred location instead of purchasing the goods at disparate physical stores, increasing the number of freight movements, which is even more aggravating when considering that each parcel is often small [1]. The last mile, furthermore, is a significant component of the parcel delivery cost, which usually comprises close to $50 \%$ of the total cost [2], and is often characterized as the most polluting and inefficient part of the supply chain [3]. Thus, minimizing the environmental and economic impacts of last-mile delivery in congested urban areas while satisfying the final customers is an important logistic challenge involving many stakeholders with different and sometimes opposing needs and constraints.

One of the ways to circumvent these challenges is to reduce freight vehicle miles traveled by establishing urban consolidation centers (UCCs) which enable the collaboration 
between shippers, carriers and retailers with the goal of consolidating deliveries. Typically, this consolidation tends to decrease the number of required delivery trips between the distribution center and the final delivery destination [4]. The UCCs were first planned and implemented in a number of European cities, particularly in France, Germany, Italy, the Netherlands and the UK, and in Japan, mostly over the two past decades. Their success and economic self-sustainability depend on several factors such as the level of involvement and cooperation of the different last-mile actors (shippers, carriers and retailers) during the early stages of the project, the financial support of public institutions, the local regulatory restrictions and the location of the UCCs and the quantity of services offered [5-7].

An additional last-mile logistics solution is the development of collection-and-delivery points (CDP) and automated lockers in urban areas, thereby offering more flexible delivery options for the customers. This alternative to home delivery can also be viewed as a commercial effort to diversify the deliveries options to meet the customer preferences. For example, in France, more than $20 \%$ of goods are delivered through a CDP [8]. Moreover, mostly due to the well-known frequency of failed first-time home delivery attempts, the CDP delivery option reduces the travel and environmental costs compared with the later option [9].

A micro-depot (MD) is a logistics facility usually located inside or close by an urban area, in which a logistics service provider (LSP) can load or unload, sort, store, and deliver parcels from it to the end-receiver. The use of MDs generates two outcomes: consolidation of deliveries (which is why MDs are also known as micro-consolidation centers $[10,11])$ and employment of vehicles in the last-mile delivery that are less harmful to the environment [12], such as cargo bikes. An MD can also be a CDP, in the sense that parcel lockers can be installed and customers can pick up or deliver their parcels from/to there. MDs have been in use since the early 2010s, usually by large well-established LSPs [12], but typically as a facility for a single company use [10,12-14], such as Amazon and UPS lockers. A shared MD is an MD whose facility is used by many LSPs, who can operate independently or have a single white-label company operating on behalf of all of them. As mentioned above, UCCs have to cope with many challenges in order to be financially viable; thus increasing the number of LSPs having access to a given MD and consolidating its use should be alleviate many of the financial challenges.

We introduce, in this paper, the-so far unique-concept of a shared MD network for last-mile logistics with parcel lockers and auxiliary business models. Our research idea paper's intention is to define a new last-mile logistics solution for future academic research and real case studies in multiple cities. The shared component we propose, thus, is an innovation that can yield cost reduction, improved customer service, and reduced congestion, noise and air pollution. The shared MD concept was tested in the real world as part of the Shared Micro-depot for Urban pickup and Delivery (S.M.U.D.) project. This project consisted of a consortium of cities, research institutes and an architectural design firm whose goal was to provide an attractive solution to business-to-consumer (B2C) small parcel last-mile delivery that benefits cities, residents, and businesses. Over the course of a year, the cities of Helsinki (FI) and Helmond (NL) served as testbeds for this new logistics concept. In Helsinki, one strategically located MD was shared by five business partners and served as both a transshipment point and CDP. In contrast, in Helmond, the initial focus was mapping customers' and residents' needs, and aligning them with the local authority's vision of a green and smart city, and with the business partners' operational processes.

The main takeaways from our case studies are that support from local authorities is vital from the beginning of planning. The location of a shared MD is extremely important, both for business partners and city residents, and for customers' acceptance; sharing a facility (and a business) is only possible when there is transparency and trust among two business partners; and for the sharing to work, moreover, it is our experience that it is better for a third-party entity to oversee the shared MD's operation, so that each LSP can handle its business without the concerns of the entire network. 
This paper is organized as follows. Section 2 presents a literature review; Section 3 discusses the case studies from Helsinki and Helmond, as well as providing alternative implementations for a shared MD; Section 4 describes how one can assess the success of implementing a shared MD network; finally, Section 5 concludes our work.

\section{Literature Review}

During the last decade, with the rapid growth of online shopping, which has increased the congestion and emissions in cities, the number of academic studies in the area of lastmile logistics has significantly increased [15-17], where sustainability is the key objective. In particular, multiple-echelon distribution strategy is a modern trend where the delivery of parcels from the initial distribution center to the final customer is done through intermediate and typically small depots in order to minimize the total transportation cost of the vehicles involved in the deliver process $[18,19]$. Special attention is given to the complex urban parcel delivery system, because of obvious environmental and social issues [20]; the emergence of sustainable mobility is fueling an increase in the number of research and projects of last-mile delivery in cities.

Numerous mobile depot [21], micro-depot [11,22] and urban consolidation center (UCC) $[4,18,23-27]$ solutions have been implemented in several cities and reviewed in the literature. The work [14] is the first to present the use of a trailer as a mobile depot in an urban area. In their pilot studies in Brussels, in the morning, this mobile depot parks in a parking location in the city. Then, electric cargo bikes pick up parcels from the mobile depot and convey them to their final destination. This pilot study was conducted in cooperation with an international LSP. The authors [14] discuss the sustainable, social and economic effects of this new concept on the different involved stakeholders, using a multi-actor multi-criteria analysis (MAMCA). The survey's results show that the mobile depot is a profitable solution for all stakeholders (residents, city, LSPs and customers), except for the LSP itself, because of excessive required costs. The analysis also reveals that internalizing external costs, increasing the capacity use of the depot and the drop density would be more economically viable for the LSP. In particular, this work demonstrates the need to share costs with other LSPs, as, among other things, we propose in the present study.

The mobile depot presented in [28] circles the city and only parks when loading and unloading. Thus, this configuration requires less urban space than the solution of [14] and decreases the economic cost of the LSP. Nevertheless, the congestion and the pollution could be reduced further because the suggested mobile depot is neither electric or small. Moreover, these solutions do not propose the installation of parcel lockers, which enable customers to pick up their own deliveries from the depot and reduce the last-mile delivery. Indeed, the inclusion of different delivery modes, such as green vehicles, bikes and parcel lockers, enables this last-mile logistics solution to be more sustainable [29].

Ref. [30] addresses a MAMCA framework to evaluate the social, environmental and economic impacts of freight consolidation policies in an urban environment that consider the objectives and the constraints of all stakeholders involved in the solution. Ref. [31] conduct a simulation study on the UCCs in the city of Copenhagen. They test and analyse several schemes, where a scheme is defined by its combination of administration measures and costs settings.

Multiple articles highlight the importance of the UCCs and MDs' location; several mathematical and quantitative models support this decision problem by considering sustainable constraints [32-35].

In urban environments, available space is a serious constraint, because in most cities, it is rare and has a prohibitive cost. Thus, MDs have been implemented in many cities, such as Manhattan [22] and London [10], in order to optimize last-mile logistics. Moreover, the literature proposes and analyzes the introduction of parcel lockers in last-mile logistics [36-38]; final customers can collect their deliveries whenever it is convenient for them, and it may avoid the problems involved with home deliveries, while reducing the environment impact. 
The present paper differs from most of the concepts of last-mile logistics developed in the literature so far, by proposing a micro UCC in an urban environment that is shared by multiple LSPs-in other words, a shared MD network. Indeed, in the logistic solutions proposed above, the costs of the depot are supported by one LSP, which have a negative effect on the economic viability of the projects. We propose a shared MD, which can be utilized and financially supported by several LSPs. The solution proposed in this paper is related to the mathematical model formulated in [39]; indeed, the authors define a mixed integer programming problem for solving the urban last-mile delivery issue, by assuming that urban depots can be jointly used by multiple LSPs. They show that optimal usage of shared spaces enhanced by multiple delivery options in cities helps to decrease the operational, economic and environmental costs with respect to the single-echelon policy, while focusing on customers' delivery option preferences. Their methodology is theoretical, whereas our approach is empirical, since real case studies support our proposed solution. Moreover, the shared MD network concept that we propose here is flexible enough to integrate parcel lockers as CDPs and auxiliary business models, which may be economically profitable for the LSPs and sociably profitable for residents.

\section{Implementation of a Shared MD Network}

In this section, we explore four topics. The first one addresses a case study from Helsinki, where a pilot for a single shared MD ran for six months. The second explores a case study from Helmond and we present the municipality's planning phase for future implementation of a shared MD network. The Section 3 discusses other approaches for a shared MD network, as well as a roadmap followed by Munich to implement shared MDs in the city. In the Section 4, we propose a framework that categorizes possible auxiliary business models to guide municipalities and companies willing to invest in the concept of a shared MD network.

\subsection{Helsinki Case Study}

A wood cottage built in Helsinki's center with two containers parked outside, next to one of the city's most key bicycle lanes, served as a shared MD for six months. There were five business partners involved in this operation: a 24/7 parcel locker company; a magazine publisher that had its daily magazines delivered by cargo bikes by a third-party LSP; a large LSP using the MD as a transshipment point, delivering from its depot to the MD by either a van or a truck and from the MD to the customers by cargo bikes; and a startup providing crowd-sourced deliveries. The shared MD was under the responsibility of the municipality, which provided cleaning and security to the facility.

Each LSP operated independently, only sharing the location. Since they used cargo bikes for their last-mile deliveries, their target delivery area was set to around $10 \mathrm{~km}^{2}$, covering both residential and principal business areas in the city. Deliveries are carried out the day after the pickup of goods at the sender.

The vehicles used by the LSPs when delivering to the shared MD were trucks or vans and each LSP needed one to two trips to the shared MD per day, depending on the respective LSP's daily volume. It is important to note that pickups were carried out along the way as well; the vehicles, therefore, could not be used at full capacity. The vehicles that went from the shared MD to the customers were mostly cargo bikes, but electric vans could be used as well. Cargo bikes have a capacity of $1 \mathrm{~m}^{3}$, carrying out 30 to 40 shipments, and each cargo bike was able to do three or four trips a day. The vehicles were stored overnight in the garage and loaded in the morning. The cargo bikes were the property of the LSPs. The quantity of orders processed in a day depended on the demand; on a busy day, however, the MD could expect to process around 200 parcels. The time window for the deliveries/pickup was from 08:00 to 16:00 and, typically, the goods were delivered in the morning and pickups were carried out in the afternoon.

The location is fundamental for success. In fact, the LSPs in the pilot stated that the location the municipality provided was the main reason for their participation. Neverthe- 
less, not only is location crucial from an operational point of view, but the right kind of facilities is also essential for a suitable delivery operation. The main facilities needed for the shared MD were unloading space for trucks/vans, a small warehousing space and space dedicated to the cargo bikes. Moreover, given Helsinki's winter temperatures, the MD required good equipment/clothes and changing rooms. In general, considering MD facilities, it is also important to understand the building permit policy of the city.

The pilot received positive feedback from residents who picked up parcels or passed by the MD. In particular, the MD's social effect; that is, many by-passers used the MD as a social gathering point and it became a place for many people to rest in the middle of the day.

The companies involved with the pilot reported an efficiency increase when delivering from the MD to more dense areas. We also saw, from the pilot study, that having a thirdparty operator impacts positively the LSPs' work and we feel that it is a necessity to ensure sustainability in the long term, so that each LSP can handle its operations without having to oversee all other LSPs. Understandably, each LSP has its own opinion about the way it operates and what it needs for operating. When adding the shared-facility component, the operation is more complicated. From this experience, the initial lack of trust of sharing a space with the competitor was one among many obstacles in establishing a shared MD. The right business partnerships, therefore, are a vital criterion for the success of a shared MD. When an MD has business partners that operate independently, the daily operation flows easily.

\subsection{Helmond Case Study}

The city of Helmond is developing a new district, whose aim is to be the smartest district in the world. The Brainport Smart District (BSD) will accommodate 1500 homes and 12 acres of business grounds. The implementation of a shared MD network is part of the BSD mobility program. Only emission-free vehicles will be allowed into the district; the concept, therefore, is to locate the first shared MD outside but right next to the district. From there, cargo bikes or light electric vehicles will service the last mile. In the process of planning the new district and, in particular, the shared MD, local authorities consulted two types of stakeholders: future residents and business partners.

A survey was conducted among 152 of the future residents of BSD, and we show the results in Figure 1. From these, we see that $65 \%$ order online monthly and 55\% stated that they stared ordering more due to COVID-19 effects. Moreover, $71 \%$ of the respondents prefer home delivery over having to pickup items by themselves, with more than $25 \%$ of these respondents finding the latter option annoying. Almost two-thirds of the respondents are willing to pay to use an MD; however, this willingness depends highly on the cost. The survey's results show that the residents would consider the proposed logistics solution as attractive if it includes the following features:

- $24 / 7$ open

- Safety

- Close to home

- Notification of delivery

- $\quad$ Easy access

- All LSPs participate.

The dialogue with business partners was conducted, mostly, in virtual workshops. Eight potential business partners gathered to define their objectives, establish a common vision and create a relationship. The main topics discussed were legal requirements, operational model and social function of the location. They assessed that a large LSP does not need a shared MD to deliver parcels sustainably, but small LSPs do. The only reason to compel a large LSP to use a shared MD, thus, would be if it had no other way of reaching the customers' homes. The potential business partners also stated that it is difficult to share data among companies, because alongside the need for a common system, there is also initial mistrust. A shared MD, hence, should have a common service for customers, but not 
for the LSPs delivering to the location. Another takeaway is that CDPs are only relevant if customers are ready to waive the convenience of receiving home-delivered parcels. Most customers here in the Netherlands, it was agreed, are not yet prepared to cede this luxury.

The preference in the BSD shared MD is, therefore, for white-label deliveries, which means one organization being responsible for the entire operation of the shared MD; in particular, the last-mile delivery to customers' homes. LSPs would unload their parcels at the MD, and the white-label delivery would happen from there. This white-label organization, hence, would have to be, legally, a new entity itself. An option would be for all LSPs involved to have a share in this new organization and, in this way, commit to its success. The goal, in Helmond, is to forge the white-label organization even before building the shared MD.

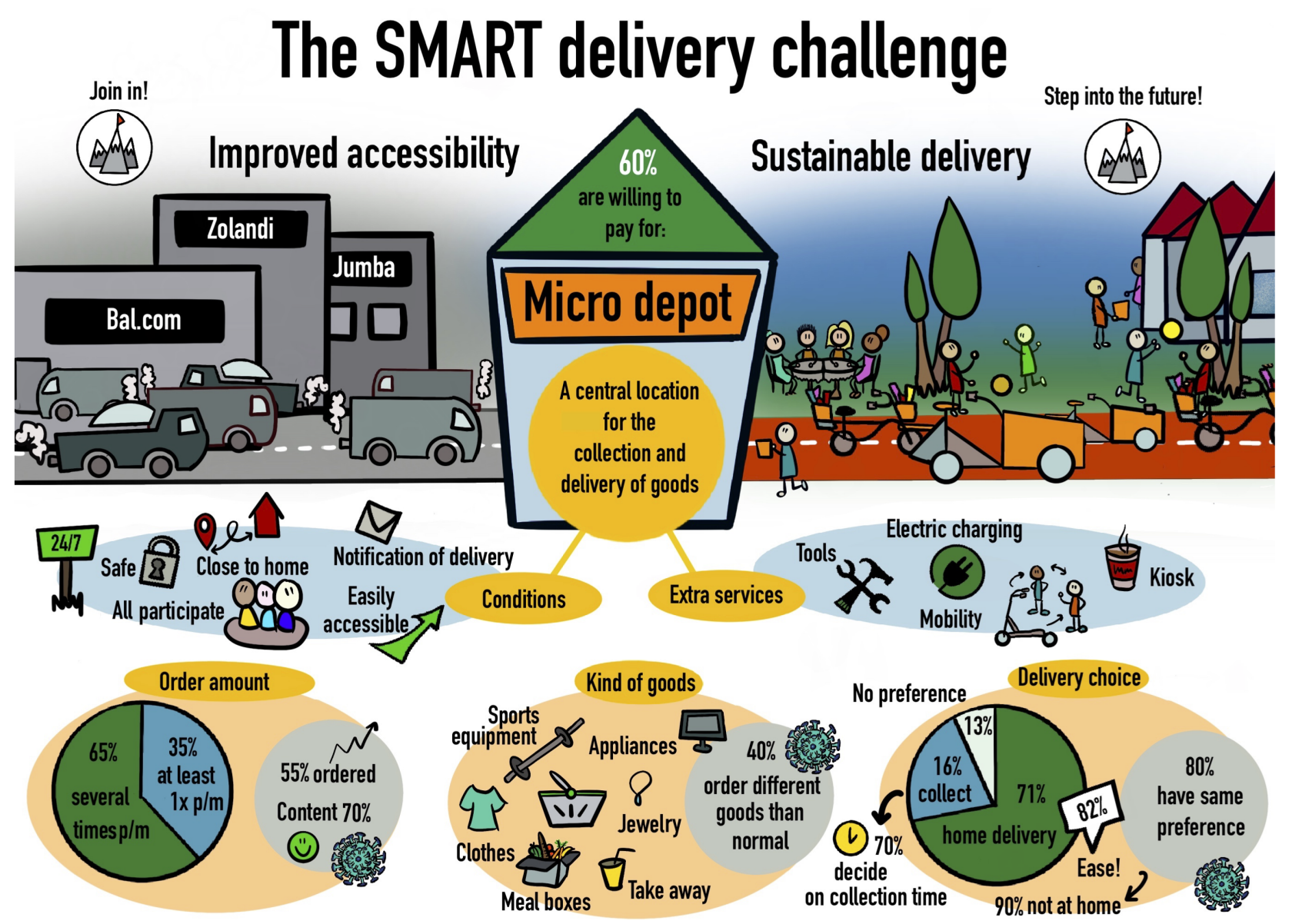

Figure 1. Results of the survey among future Brainport Smart District (BSD) residents. Illustration from [40].

In the discussions, the legality issue was one of the main questions raised. From the legal perspective, a purchase is a contract between two parties (the customer and the vendor). When using a third-party service to have an order delivered, there is an additional contract between the vendor and the LSP. Such arrangements intend to protect each party against problems that may occur on the way. Using a new organization in between, however, has not yet been protected against possible liabilities. It is, therefore, crucial that insurance companies be brought into the discussion, which is one of the next steps. Apart from legal issues, the new company also needs an efficient process for handling deliveries for multiple LSPs. It is important to use current expertise of the companies involved, as well as train new personnel. 
One of the next steps in establishing the shared MD network in BSD is to regulate its use. Ideally, the policy should be that only a white-label organization is allowed to delivery into the district and that this last-mile delivery should be by bikes or light electric vehicles. The authorities are examining the alternatives here.

\subsection{Extensions of shared $M D$ s}

Parcel lockers can play many roles in the shared MD network. In the Helsinki case study (Section 3.1), they were installed at the MD; however, that is not the only option. It is possible to establish parcel lockers in central locations, without the other logistics perks of an MD (transshipment of goods, for example). A central location is a place where many people often pass by, such as transportation hubs or close to multiple commercial buildings. This way, multiple demand points can be aggregated, the number of deliveries needed to satisfy the demand can be decreased and failed deliveries averted, avoiding second or more deliveries.

A different approach would be to use parcel lockers as an extension of the network (either by local government imposing traffic restrictions or because they are cost effective), thus, reaching isolated or less accessible regions that would not be served otherwise. In a cargo bike trip from the MD to the customers, it is possible to add a stop at a parcel locker as well. In doing so, we can improve routing and reach more customers at the same time, as shown in Figure 2. In Figure 2b, two customers who, in Figure 2a, received their order directly from the courier go to the close-by parcel locker to retrieve it instead. Customers, who, without the use of parcel lockers would be out of reach, now can also retrieve their parcels in a nearby location.

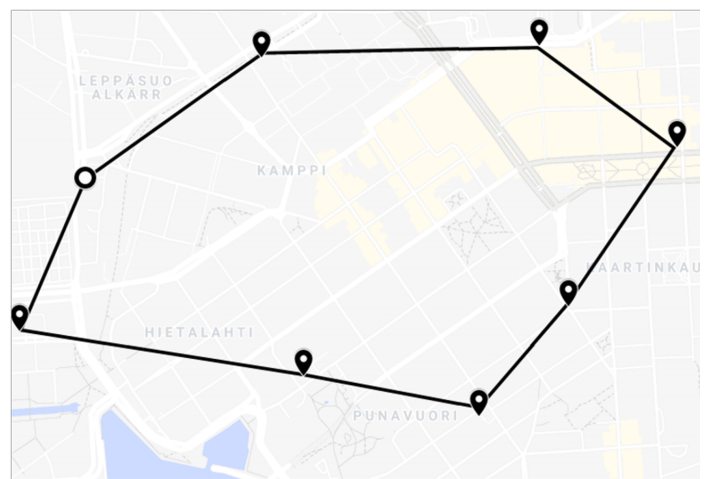

(a) A trip from the micro depot (MD) (circle) to customers, without parcel lockers.

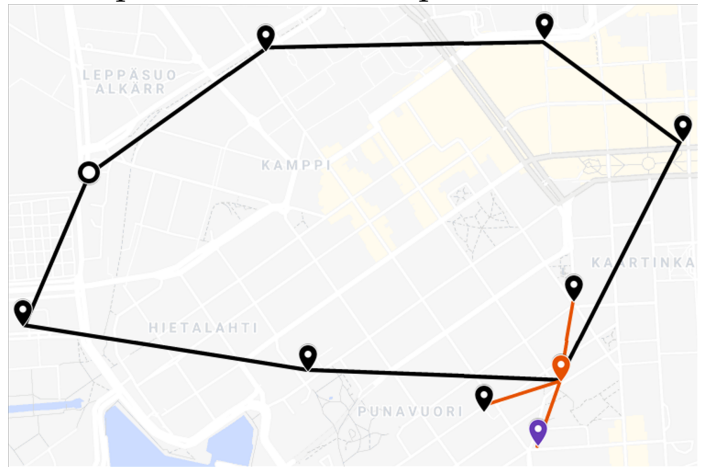

(b) A trip reaching the same customers as in Figure 2a, with the addition of parcel lockers (orange) and a new customer (purple).

Figure 2. Adding parcel lockers into a delivery trip from the MD.

A shared MD, whether it constitutes parcel lockers only or not, can be flexible and designed to fit residents' needs. They can be located in center locations, transportation hubs, residential or commercial areas, or even near vacation spots. Each MD must be matched to its location, i.e., we must take into account narrow streets, notoriously congested roads, 
the existence of bicycle lanes, vehicle access regulations, and so forth. Then, there is the decision about which kind of vehicles to use for deliveries: cargo bikes, (electric) vans or trucks. Once all the externalities have been mapped and the specific objectives for the network, such as the number of MDs needed, have been defined, the best locations for the shared MDs must be identified. This is done by a thorough location planning optimization process.

\subsection{Auxiliary Business Models for Shared MDs}

The shared MD network offers a solution to the last-mile problem in urban areas, a situation badly in need of resolution. On the one hand, last-mile logistics creates traffic congestion and generates harmful emissions, but, on the other hand, the need for frequent and convenient deliveries to customers is steadily increasing.

Given this reality, we propose to make the most of the shared MD network and solve other possible problems residents of an urban center might face. Accordingly, the auxiliary business models for MDs that we present help tailor each network to its surroundings. In other words, each city can offer different services in its networks to better suit the needs of the surrounding population. This section gives a general structure that auxiliary businesses can have and we illustrate it with a few examples.

In 2015, three quarters of the European population lived in urban areas and this number is expected to reach over $80 \%$ by 2050 [41]. This significant number reflects a reality of urban centers that can be characterized by tiny, crowded apartments, consumerism and extensive use of disposable products.

People who live in a densely populated area usually prefer to be in, what they believe to be, a good location, and this consideration generally counterbalances the option living in a larger house or apartment. Once they abdicate space, people also surrender owning convenience items, keeping in their home mostly the essentials for their daily routine. These convenience items do not necessarily have to be luxurious; they can be objects that are expensive to buy if not used very often or too large and take up more room than the residents are willing to spare.

Consumerism is characterized by low-quality products being constantly sold. They are low quality because companies need to keep selling them to continue making money. So, for example, a blender cannot have a lifespan of 20 years because then people will only buy one every 20 years. This concept of planned obsolescence is applied to different kinds of products and the European Union is aware of this problem and is already battling it [42-44]. Moreover, hectic yet comfortable modern urban life makes people believe that it is perfectly fine to use a disposable piece of plastic for only a few minutes or even seconds and then throw it away-another element of consumerism. These features result in waste accumulation and pollution. While thinking of possible auxiliary businesses for the shared MD network, we have to consider this reality and how to approach it to achieve a sustainable business in a sustainable city.

Sustainability for many of the proposed auxiliary businesses comes from, on the one hand, each being small scale. They are too small to justify their own storefront. On the other hand, each offers particular advantages to the locals because the MD will be close, very close, to the user's place of residence (or possibly another frequented location, e.g., place of work or transportation stop). The shared MD network that we consider comprises many MDs that aim to reduce the negative impact of transportation of goods inside the city, while offering multiple auxiliary businesses whose goals are to provide services that offer value to residents. We divide the auxiliary businesses into two groups:

1. Standard: Business models that involve services that are currently widely available, but that can utilize the MD structure to facilitate these services, either in terms of timeliness or cost effectiveness.

2. Enhanced: Business models that are not commonly available outside the shared MD network and can utilize the MD structure to provide services or aspects of services that are not readily feasible using home delivery. 
From the customer's point of view, there are at least three different types of auxiliary business models as shown in Figure 3. That is, customers may interact with the network in three different ways: through pickup or delivery, exchange, or making use of what we call activity space. These businesses may require different special conditions, such as electricity, temperature control, and open/closed space.

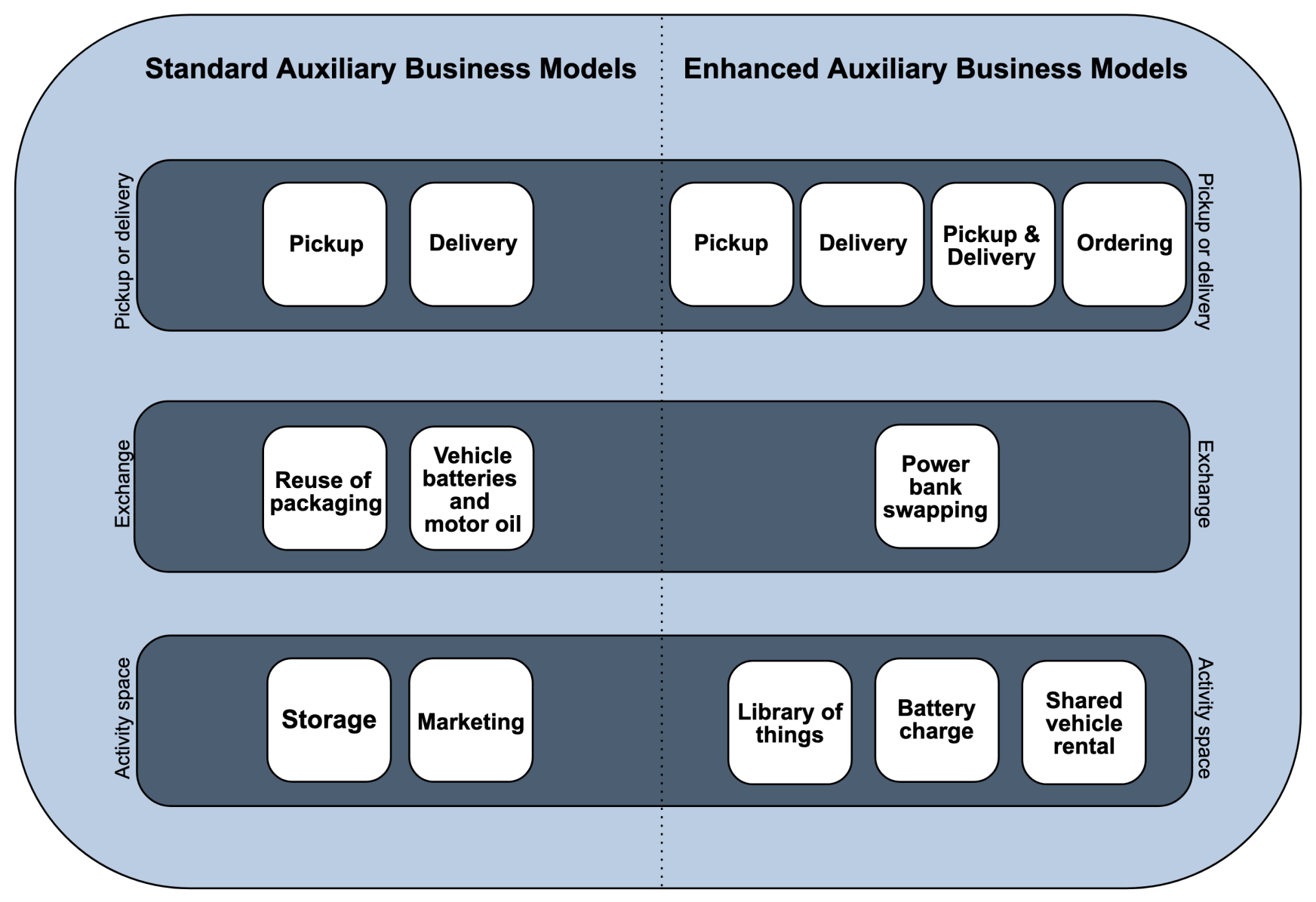

Figure 3. Auxiliary business model categorization.

There is no one-size-fits-all suite of auxiliary business models, and each implementation of an MD can provide a different solution depending on the externalities. The models that should be offered depend on many factors:

1. Culture of the population/community: Different communities have different needs, and a tailored MD deployment should recognize and meet these needs.

2. Needs of the population/community: Even within the same culture, different communities have different needs. These may arise from the current availability of services in a particular area.

3. Location of the MD: The auxiliary offerings of an MD will depend on where in the city the MD is located. To illustrate, we provide some examples:

- Residence-centered: When the MD is located close to a transportation hub, the commuting population would benefit most from auxiliary business models, such as car battery exchange (versus being less relevant if located closer to the customer's home or office).

- Work-centered: When the MD is close to where residents work, they would benefit most from auxiliary business models that allow people to run their daily errands easily during short breaktimes. 
- $\quad$ Entertainment-centered: When the MD is near entertainment/vacation spots, the auxiliary business models, such as temporary bag storage, would be beneficial.

\subsubsection{Standard Auxiliary Business Models}

The standard auxiliary business models consist of business models that are already implemented in different places throughout the world. The main difference brought by their implementation in the shared MD network is that they will benefit from the gains of using the MD structure. We categorize them in terms of three perspectives from the customer's point of view: pickup or delivery, exchange, and activity space.

\subsubsection{Pickup or Delivery}

The pickup or delivery businesses are based on reaching the customer at her or his home (or other convenient locations such as transportation stops or place of work). For this standard case, they are subdivided into two groups from the customer's point of view: pickup and delivery.

\subsubsection{Pickup}

The pickup service operates when the transportation company working for the closest MD goes to the customer and picks up an item to be delivered somewhere else. This can be done for regular mail and parcels by scheduling a pickup time upfront.

Reverse logistics: The European Union has mandated that producers are now responsible for recycling their products [45] and MDs can play a huge part in this. MDs can forge partnerships with manufacturers so that they will pay the MDs to collect and ship products that customers return for recycling. Customers could receive payment for turning in products for recycling, such as what already happens when returning glass bottles. An example would be furniture recycling: manufacturers can reuse good material from old furniture to produce new products instead of using new raw material. This helps create a circular economy and reduce our consumption of natural resources.

\subsubsection{Delivery}

The delivery service operates when the transportation company working for the closest MD goes to the customer and delivers an item. This can be done for regular mail and parcels ordered online.

\subsubsection{Exchange}

The exchange business models have, at their core, the fact that both parties-the customer and the business-both give and receive something during the transaction. This exchange can occur by giving an item and receiving a different item or by the customer giving an item and receiving something in return from the business, either an object or a service.

Reuse of Glass Bottles: In the (very) old days, a milkman would deliver fresh milk to people's homes and collect their empty bottles on the same trip [46]. The concept of recycling may, at first, seem like taking a step backwards in time, with citizens ceding a bit of the convenience of modern day life. Nevertheless, when exchanging empty glass bottles for full new ones, we are reducing the use of plastic and limiting the number of glass bottles that are needed. In one model, customers would either have their bottles picked up at home or go to the MD with their empty bottles and receive monetary credit for them. This credit could be used immediately or in the future for purchase of new full bottles. Customers would pay a higher cost for a full bottle at first, but as they return bottles, they would receive a discounted price. This model could be applied to returning empty milk/soda/beer/wine bottles and getting filled new ones, and to many other retail products that can have reusable packaging. Packaging cleaning products, coffee, personal hygiene items such as deodorant and shampoo in reusable containers are just a few examples of what can be done to create a more circular and less wasteful economy. 
Vehicle Batteries and Motor Oil: In another model, when an automotive battery dies, customers could order a new battery to be delivered to their home or to the nearest MD and then turn in the old battery sometime afterward. Alternatively, they can have the new battery delivered to them while the old battery is collected in parallel at the same moment. This is particularly useful, since when a battery dies, it is expensive to move the car and obtaining a new battery is particularly difficult. Being able to return the old battery when receiving the new one is essential for environmental reasons. In fact, it is illegal to dispose of automotive batteries in landfill sites or to incinerate them [47]. For motor oil, the same principles apply, since one cannot dispose of this oil as one pleases. Having the oil changed at one's convenience, either at home or at the nearest MD, which would be much closer than a service station, would be of great value for the customer.

\subsubsection{Activity Space}

When the customers interact directly with the physical structure of the MD, they are actively using the MD space. Therefore, the activity space business models require the customer to eventually be present at the MD.

Storage: Using the structure provided by the MD to store customers' items in lockers or storage units.

Small items for a short period of time: If one is away from home or out of the office, and does not want to wander around with heavy items, or if one wants to leave a document/package for someone else to pick up, renting lockers is an effective way to keep items safe and not have to carry them at all times. MDs would provide space and safety. Using an MD in this way would allow the exchange of goods between two ordinary citizens without the need for them to physically meet. All they would have to do is send a code. This would be made possible by renting a locker for a period of time.

Larger items for a longer period of time: In the case of having to vacate a home or office, and not yet having a place to move into, or if there are objects that are too big to keep at home and are not used very often, placing them in a nearby MD could possibly help. Self-storage unit rentals at the nearest MD would only be available at large versions of the shared MDs, given the necessity for enough room to store large items at a close-to-home location.

\subsubsection{Marketing}

There could be screens inside the MD, in the customer service area, with multiple paid advertisements or government announcements. In addition, affixed to the MD's exterior, there could be paid wall advertisements or government announcements.

\subsubsection{Enhanced Auxiliary Business Models}

The business model ideas presented in this section are enhanced because they rely heavily on the network structure. They are made possible either by the consolidation of services or by the mandatory use by customers of the MD facility. Without these preconditions, these models are either infeasible or not relevant. The use of the same MD space by different businesses also adds more value to the customer and to the real estate located in a high-density area. Instead of having many locations, each one serving a single purpose and perhaps being idle for extended periods, the shared component minimizes the negative effect on the community, by making the most of fewer resources. Moreover, it is possible for different auxiliary businesses to share the same human resources, thus preventing the MD from becoming overcrowded with personnel not related to its core business. We divide the enhanced auxiliary business into three, as in Section 3.4.1: pickup or delivery, exchange and activity space.

\section{Pickup or Delivery}

In the enhanced business models for pickup or delivery, the structure of the MD is a fundamental part of the user experience. The interaction between the customer and the 
MD directly at the MD is the main difference from what was presented in Section 3.4.1.1. Notice that since this is a shared network, there is a single point of interaction. Given that in this model the customer comes to the MD, we add two new possibilities besides pickup and delivery: pickup and delivery and ordering. The business models in this part, accordingly, also include ordering. Pickup uses the infrastructure of the MD not only to improve the process, but also as a fundamental part of the business core. The delivery component allows the customer to order personalized items at the MD.

Pickup

The customer goes to the MD to pick up an item either with human interaction or through lockers. MDs would offer shared or dedicated lockers for third-party companies to use as delivery points for online shopping. The lockers could either have or not have a refrigeration system. This could be preferable to home delivery, as it would release the customer from having to wait at home for the delivery. The attractiveness would depend on the proximity of the MD to the person's place of residence. Examples would be groceries, general e-commerce, meal and takeout food services.

Delivery

The customer goes to the MD to deliver an item, either with human interaction or through lockers. MDs would offer shared or dedicated lockers for third-party companies to use as CDPs. With this system, the customer could send items, using the locker, for the MD company to deliver to its final destination. This works for common mail and parcel delivery and it eliminates the need for the company to go directly to the customer's home or the other way around, since the MD is meant to be close.

\section{Pickup \& Delivery}

Providing a service vis-à-vis an item: The customer goes to the MD to pick up/deliver an item, either with human interaction or through lockers. This item will receive a service. MDs would offer shared or dedicated lockers for third-party companies to use as pickup and delivery points. With this system, the customer could collect and/or send items through the locker for the company to provide its service. An example would be a laundry service: customers could drop-off their clothes and a laundry company would collect them, wash/dry-clean them and return them to the locker in a preestablished amount of time. Payment could be made on site to the laundry company using an intelligent system. Another example would be technical support for laptops, in which the customer would send their computer for analysis and then receive the laptop back after repair.

Many-for-one home service: MDs can offer two or more services at once when interacting with the customer, which generates more value to the system, as well as to the customer. This is made possible by the shared component of the network. That is, the consolidation happens, given the shared facility and transport of multiple players, and allows different services to reach the customer together. With the consolidation, it is also possible to arrange a specific day for all items to be home-delivered together. This service is already provided to Amazon Prime users who can benefit from Amazon Day [48]. Possible examples of many-for-one home services would be combining pickup/delivery of parcels and mail, pickup/delivery of laundry, pickup of waste and recyclable items at a single visit to a customer or pickup of personal items to be stored or delivery of items that were stored.

\section{Ordering}

MDs would offer a catalog of products that need to be personalized for each customer in a unique way. In this way, the customer would have to go to an MD to check the options and make their choice on the spot. This system would enable customers to order the correct product from a close-to-home location. After ordering, the product can be sent directly to the MD or the customer's home. Two possible examples are: 
Paint ordering: The MD would have a color palette. Customers would be able to use the palette to order paint without leaving the vicinity of their home, instead of paying for a color-fan that would be barely used. They could also easily take the palette to their home and conveniently return it to the MD. A color palette is expensive in relation to the number of times an individual uses it and being able to physically see the colors ensures that the customer sees the real color and not that presented on a computer screen, which is not true color.

Eyeglasses ordering: The MD would work as an eyeglass frame showcase, with multiple frames available. Once a customer picks a frame, the MD would order a frame with the correct lenses for the customer. The customer, then, would pick them up in a couple of days or have them sent to their home.

\section{Exchange}

The exchange in the enhanced models occurs when the exchange transpires in the MD facility and is part of its core operations. That is, the action of swapping objects and/or services occurs inside the MD instead of at the customer's home.

\section{Power Bank Swapping}

Notice that MDs must have a power source to run its normal operations and thus having power for battery charging is available by default. Customers would pay a monthly/yearly fee and they would carry a power bank with them. In the case of dying battery, they could turn in their power bank and grab a full one. This way, they would not have to charge it when depleted, but only swap it at the nearest MD.

\section{Activity Space}

The activity space for enhanced business models focuses on the concept of sharing. The idea of shared MDs is cooperation with improve business and urban lifestyles on different fronts. Its aim is to promote a more sustainable lifestyle and avoid cluttering small homes. One of these fronts is helping citizens make do with limited resources, be it lack of space, money or time. The activity space also provides value for the community that it is adjacent to the MD, since its residents would participate in the shared and circular economy.

\section{Library of Things}

MDs would have a space whose purpose is to store items that people typically do not use very often, are expensive and/or are too large to be kept in a small house or apartment. Customers would rent these items for a limited amount of time (different times for different kinds of items). Such items could be, but are not limited to:

- $\quad$ Beach equipment (chairs, parasol, cooler, floaters, etc.)

- Kitchen equipment (grinder, pasta machine, blender, food processor, mixer, juicer, barbecue grill, etc.)

- Tools (drill, nail gun, standard toolbox, power saw, steam cleaner, etc.)

- $\quad$ Party accessories (large hot water urn, hot plate, punch bowl, sound system, etc.)

- $\quad$ Luggage, suitcases, duffel bags

- $\quad$ Gym equipment (dumbbells, steps, rope, mat, jump trampoline, etc.)

- Specific weather gear (umbrella, raincoat, windbreak coat, scarf, gloves, blanket, fan, etc.)

This service could be modularized, i.e., each line of products is independent of the others. This allows tailored MD service for the area in which the facility is located. For example, a beach module is only reasonable in cities that have a beach.

\section{Battery Charge}

Phone-charge locker: There would be lockers at the MDs and in them an energy outlet with charger cables for different phone models. Customers could leave their phones inside the locker while charging. 
Cars (electric): Outside each MD, there could be a number of charging stations for electric cars.

\section{Shared Vehicle Rental}

Both locals and tourists could profit from using shared vehicles to get around the city. Although for many city inhabitants, owning their own car is not a necessity, sometimes they need a car to transport large objects or other people around town or for a quick getaway outside the urban area. This type of rental empowers people to get to places not reachable by public transportation. This would be offered as shared electric cars and bicycles.

\section{Assessing the Success of a Shared MD Implementation}

There are many ways of measuring success. One has to consider both who we are concerned with and what dimension we are interested in evaluating success. For the first part, i.e., who we are concerned with, we consider all stakeholders, that is, residents, local authorities (e.g., cities), customers (i.e., those receiving the packages) and businesses (e.g., LSPs). For the second part, i.e., what dimension we are interested in evaluating, we consider the triple bottom line of sustainability, i.e., environmental, economic, and social [49].

To understand the impact of a shared MD, it is instructive to look at a typical day at an imagined shared MD. We compare two scenarios: Scenario 1, with a shared MD and Scenario 2, Status quo.

Scenario 1: With a shared MD

A shared MD operator establishes a cooperative arrangement with an LSP to distribute packages in the heart of a city where they are to jointly test carbon neutral last-mile logistics. The status quo has the LPS' last-mile logistics mostly run from the LSP' main warehouses outside the city center. This means that the status quo has multiple LSP vans drive into the city center each day to deliver parcels in areas near the city center.

In the scope of the new paradigm, instead of delivering parcels to customers in the city center using vans, the LSPs make their deliveries to the MD. The MD then takes over the last-mile delivery for all LSPs. Because of the density of customers and their proximity to the shared MD, manually operated cargo bikes are used for the last-mile delivery.

For one LSP, the distance between its warehouse and the shared MD is $14 \mathrm{~km}$ using the shortest route. The shortest route, however, is not always used, since the vehicle may also continue to deliver packages to customers outside the area covered by the shared MD.

On a particular day, the demand in the area covered by the shared MD is 75 parcels for delivery/pick-up, and approximately 25 more outside the area covered by the MD. In this case, the shared MD is supplied from the distribution center using two different routes. The first delivery route, as it is a dedicated delivery to the MD, is $14 \mathrm{~km}$ long. The second route is longer because the vehicle is also delivering to all customers outside the area covered by the MD. The length of this route is $80 \mathrm{~km}$.

In addition to the vehicles, the shared MD involves having and operating the facility for the whole day.

\section{Scenario 2: Status quo}

In this scenario, instead of distribution to the MD for it to handle last-mile delivery, all transport services are done from the distribution center. Hence, there is only one delivery vehicle, and all the parcels that were delivered by cargo bikes, in Scenario 1 are performed by vans.

To compare both scenarios, we assume that the transportation that is not done using cargo bikes is carried out by the same type of van in both scenarios. 


\subsection{Environmental Bottom Line}

Three aspects of the environmental impact of shared MDs are greenhouse gas (GHG) emissions, air pollutants, and noise.

\subsubsection{GHG Emissions}

GHG emissions arise from the use of fuels and electricity during transport and MD processes. These can be direct emissions from burning fuels (e.g., vehicles or heating equipment at a depot), leaked refrigerants in case of temperature-controlled vehicles or facilities, as well as indirect emissions caused by the supply of energy (e.g., diesel or electricity).

The vehicles that must be considered are both the vehicles that deliver to the shared MDs from the depots located outside the urban areas and the vehicles from the shared MDs to the customers. The delivery from the shared MDs to the customers are often carried out by cargo bikes, using either manual power and/or electricity. The facilities that are being considered are the shared MDs.

The GHG emissions mentioned above are not the environmental impact of the shared MDs. On the contrary, one needs to consider the GHG emissions that are 'saved' by the shared MD network. In particular, without a shared MD network, the logistic operations of the shared MD network will be carried out in its current form, i.e., status quo. The status quo emissions must be compared to the emissions that are would be saved by the shared MD network and generated over a single day. As the number of shared MDs increase and the amount of sharing increases, the GHG emission savings compared to the status quo will clearly increase.

In comparing the two scenarios and actually going through the detailed calculations, we find that using a shared MD saves considerable GHG emissions for this example. This is the case even when including, as we must, the GHG emissions from the shared MD facility for the whole day.

\subsubsection{Air Pollutants}

Whereas air pollutants are not the same as GHG emissions, they often have the same source. The GHG emissions reduction discussed above for using a shared MD mainly comes from reduced use of vehicles-which also translates into reduced air pollutants.

Air pollution in city centers is of particular concern, and here, we can see a big difference between the two scenarios discussed regarding GHG emissions. In Scenario 2 (status quo), a van makes 75 stops in the city center, spending a considerable time (and exhaust emissions) in the city center. In contrast, in Scenario 1 (shared MD), the van only makes one quick stop.

\subsubsection{Noise}

The noise reduction from using the shared MD is considerable. The noise generated by a standard van (approximately $80 \mathrm{~dB} 9$ ) is approximately sixteen times that generated by a cargo bike (approx. 40dB10). Since the decibel scale is logarithmic, an increase in 10 decibels $(\mathrm{dB})$ is a doubling of noise volume.

As we discussed in relationship to air pollutants, under both scenarios, a (noisy) van enters the city center. Under the shared MD scenario, however, it does not go into the city center, going only as far as the shared MD to make a quick stop; but under the status quo scenario, it travels through the city center, making 75 stops.

\subsection{Economic Bottom Line}

A major indicator for assessing the benefits of shared MDs concerns logistics costs. Logistics costs can be both monetary and not directly monetary. Some examples of monetary costs that may be associated with a shared MD are: facility rental, transportation, material handling, personnel (salary of the individual driving a delivery truck and, possibly, the individual operating the shared MD), maintenance, administration, and electricity. Some 
examples of non-monetary costs are: impact on the environment and residents by the emissions from the truck that is being driven, noise, road congestion, lost opportunity cost of shared MD land use, friction between groups/individuals using the shared MD, and customer experience in receiving and dropping off packages.

If the total logistics costs are reduced, and especially if the social logistics costs (i.e., including externalities on the customer and other stakeholders), we may be able to view a shared MD as being a success from a logistics costs point of view. It is not, however, enough to reduce the social logistics cost; the bigger challenge is to reduce the costs of every stakeholder. Indeed, if one of the stakeholders is not satisfied, the project may fail.

\subsubsection{Monetary Logistics Costs}

Here, we present some of the monetary logistics costs, each from the point of view of a different stakeholder:

(LSPs:) The most important monetary cost for an LSP is the cost of delivering a package. Implementing shared MDs have the potential of decreasing delivery costs by combining geographically close final destinations from different LSPs into a single delivery route. Delivery costs could also be reduced, since the delivery options offered by the shared MD create greater flexibility in the delivery scheduling.

On the other hand, the shared MD creates additional movement and hand-offs of each package. Instead of going directly from the distribution center to the customer, each package now goes through the MD. This added complexity could increase damage to the packages and add additional insurance costs.

(Customer:) Customers, i.e., those receiving the delivery, also have their own monetary (receiving) delivery costs. If the shared MD has a parcel locker, then customers can choose between home delivery and using the parcel lockers, which can only reduce their costs.

(Residents:) Monetary logistics costs from the point of view of the residents in the area of the shared MD include lost opportunity cost of the land. On the other hand, the residents also reap a monetary benefit from the rent paid by the shared MD operator and from the increased value of their residences.

(Shared MD operator:) In some cities, if the MD is widely used, the operator's costs should be compensated by the generated revenues. Nevertheless, we stress that some cities and countries may not be able to generate profits through MDs under the current framework settings.

Others economic costs and benefits must also be considered. Integrating MDs into the urban environment should create opportunities for municipalities to benefit from using the shared MDs to provide auxiliary services and facilities as discussed in Section 3.4.

In some cases, the monetary logistics cost for some stakeholders may go down, while for others, it may go up. If, however, the monetary logistics costs go down for all stakeholders (i.e., is pareto dominating), then we will be able to conclude that the new scenario with the shared MDs outperforms the status quo.

\subsubsection{Non-Monetary Logistics Costs}

We now explore important non-monetary logistics costs, each from the point of view of a different stakeholder:

(LSPs:) The ability to track what has happened to a package and to assign liability when something goes wrong is of concern with a shared MD. If a customer opens her package and discovers that her new vase is broken, someone has to pay.

(Customer:) Making the customer experience in general as positive as possible, and eliminating any friction among LSPs using the shared MD in particular, is important to the project's success. This can be addressed by making the inclusion of the shared 
MD seamlessly 'invisible' to the customer. In many ways, the customer should not be able to differentiate between a package delivered under the two scenarios presented at the beginning of this section. If the customer, however, is offered strictly more choices (e.g., combining deliveries from different LSPs into a single delivery), then the customer experience can only be improved.

(Residents:) The residents in the area of the shared MD pay by giving up the land for the shared MD and benefit from the associated reduced environmental impact and traffic congestion (discussed above).

\subsection{Social Bottom Line}

It will come as no surprise to anyone familiar with the triple bottom line of sustainability that the three dimensions are overlapping. This is what is implied by the overlapping portions of the Venn diagram that is often used to present the triple bottom line. As such, several social aspects were already discussed above. Here, we add the aspect of citizen safety. Cargo bikes are safer for residents than vans. Moreover, for many people, the presence of cargo bikes is less bothersome than the presence of vans. In both of these ways, the shared MD scenario is better than the status quo scenario.

Part of the social bottom line is the acceptance of the shared MD as part of the fabric of the city. Acceptance must come from all stakeholders.

(Public Authority:) Public authorities include all institutions of a city that are involved in urban development in terms of area, environment, transport and economy. The task of public authorities is to care about the well-being and the needs of residents. Therefore, the levels of residents' and public authorities' acceptance are correlated. Nevertheless, the public authorities might have different priorities and perspectives.

Acceptance is essential because public authorities are in charge of providing space and permissions. This acceptance depends strongly on the following success factors: (1) Clear political strategy and vision of future traffic systems and (2) space efficiency of MD solutions, (3) future-oriented image of the city, and (4) positive effects on local emissions.

(Residents:) The acceptance of shared MDs by residents is of particular importance. On the one hand, they form the group of potential customers and, on the other hand, they have to interact daily with the shared MD, even if they are not a customer on a particular day. A shared MD will affect the street congestion, noise, and pollution, as well as take up public space.

Residents usually resist change. Proactive communication when introducing shared MDs will contribute to acceptance. Increased levels of convenience and of liveability in cities enabled by the shared MDs should be emphasized.

(Customer:) While customers are clearly residents, the focus is on a different interaction with the shared MD. Customers' acceptance relates to the quality, costs and convenience of the services offered. Listening to the needs and wants of customers is essential.

Remember that customers can be found on both ends of a shipment; the customer receiving the package and the resident sending the package. In general, business customers, such as retailers, will generally require a lean, efficient, and reliable process so as not to disrupt their core businesses activities. Service and convenience are a key to high levels of acceptance. The shared MD should offer, if possible, bundling of shipments, one-time daily delivery, and a nearby convenient location.

(Business partner:) All LSPs using the shared MD, even if they are operating it, should be considered business partners. Business partners also include other companies who are involved with the shared MD in other ways, e.g., providing value-added services; see Section 3.4. For business partners, it is important to use as many 
standardized interfaces as possible. Standardization decreases implementation and software integration efforts.

Low-cost space for inner-city transshipment and storage of parcels is rare in larger cities with high population densities. LSPs will probably be happy to receive the opportunity to use a shared MD. In cities with road pricing or city-tax systems for conventional vans and trucks, the LSPs benefit even more when using cargo bikes to deliver from the shared MD.

\section{Conclusions}

In this paper, we introduced the concept of a shared MD network with parcel lockers and auxiliary business models for B2C small parcel last-mile deliveries. Our contribution to cities and business partners is to showcase studies of a shared MD network's implementation, to provide a framework for possible auxiliary businesses that can be tailored to each location, and to supply a way of measuring the implementation success. Shared MDs generate advantages for cities and their residents, customers, and business partners.

From the case studies presented, we conclude that implementing them is not an easy task; support, not necessarily financial, from local authorities dictates whether this new model of thinking about city logistics will be sustainable in the long run. The success of a shared MD close to residents also depends heavily on their acceptance of having a logistics facility in the middle of the city, and using the auxiliary services that it provides. Finding the right business partnerships, moreover, is a crucial step in ensuring that sharing an MD unfolds smoothly. The shared MD's facility, also, when operated by a third party, allows LSPs to handle their business more efficiently.

With the proposed framework for possible auxiliary businesses that would work in the shared MD network, this paper intended to help municipalities and their business partners to understand the opportunities inherent in sharing an MD: the added value for the community while improving current business operations. The idea of auxiliary businesses for the shared MD network is to make the most with limited resources and, by doing so, increase the value of the urban space used and provide residents with services that, without their consolidation at one location, would be harder to receive. Moreover, companies can think of the shared MD network as an innovation hub, where they can try new models with support from the local authority. The main construct that underpins the entire concept of auxiliary businesses at an MD is the shared component. Besides possibly resulting in reduced personnel and real estate costs, among others, the level of cooperation among business partners is, again, the critical aspect that may prove that these models are good for both the end customer and for the companies themselves.

Our assessment framework lays out valuable metrics to evaluate the establishment of a shared MD network. The three pillars (environmental, economic, and social) are important to make sure the network is sustainable in the long run. With consolidation of deliveries, fewer delivery trips would be necessary, reducing fuel consumption, GHG emissions, and traffic noise. To have public acceptance, all stakeholders need to be involved, beginning in the planning phase. Adopting pilot tests is also a good way of shaping both the service provided and residents' mindset. The costs of the network should not be neglected, and the local authority usually has to come up with the initial incentive, financially and/or through regulation and policies.

This paper developed a new idea for last-mile logistics to be considered in future academic research and tested in urban environments; as next steps, researchers could compare the implementation of a shared MD network to the current state of business. Different delivery policies may be considered. In addition, the field needs a deeper investigation of the impacts of having a white-label company operating the MD instead of each LSP working independently. Another extension of the shared MD network that may be analyzed in the future is the use of a UCC by multiple LSPs, which consolidates deliveries even more, and only one company delivering to all MDs. Future work, also, can investigate the network from the reverse perspective and analyze the impact caused on the first mile when different 
shared MD network designs are in place. There are still open questions regarding how to successfully share not only facilities, but also the business. Helmond's case study points to a direction of a possible solution; yet, other alternatives to eliminating mistrust among business partners and solving liability issues may need to be developed further.

Author Contributions: This research was carried out by several groups in several countries. Each carried out their assigned part and wrote up their part. In addition, the Technion team combined these contributions into this meaningful article. Conceptualization, Y.T.H., K.D., P.G., P.P. (Pete Pättiniemi) and S.v.U.; Formal analysis, L.N.R., Y.T.H., E.D. and P.G.; Funding acquisition, K.D.; Investigation, L.N.R., E.D. and P.G.; Project administration, K.D.; Resources, K.D., P.P. (Pete Pättiniemi), P.P. (Peter Portheine), and S.v.U.; Supervision, Y.T.H. and D.R.; Validation, P.P. (Pete Pättiniemi), P.P. (Peter Portheine) and S.v.U.; Writing—original draft, L.N.R., N.B., Y.T.H., E.D., P.G., K.D., D.R., P.P. (Pete Pättiniemi) and, P.P. (Peter Portheine) and S.v.U.; Writing—review and editing, L.N.R., N.B. and Y.T.H. All authors have read and agreed to the published version of the manuscript.

Funding: This research was funded by the EIT Urban Mobility grant 20036 for Shared micro depots for urban pickup and delivery (S.M.U.D.).

Institutional Review Board Statement: Not applicable.

Informed Consent Statement: Not applicable.

Data Availability Statement: Not applicable.

Conflicts of Interest: The authors declare no conflict of interest.

\begin{tabular}{|c|c|}
\hline \multicolumn{2}{|c|}{ Abbreviations } \\
\hline \multicolumn{2}{|c|}{$\begin{array}{l}\text { Abbreviations } \\
\text { The following abbreviations are used in this manuscript: }\end{array}$} \\
\hline BSD & Brainport Smart District \\
\hline CDP & Collection-and-delivery point \\
\hline $\mathrm{dB}$ & Decibels \\
\hline GHG & Greenhouse gas \\
\hline LSP & Logistics service provider \\
\hline MD & Micro depot \\
\hline MAMCA & Multi-actor multi-criteria analysis MAMC \\
\hline UCC & Urban consolidation center \\
\hline
\end{tabular}

\section{References}

1. Savelsbergh, M.; Van Woensel, T. City logistics: Challenges and opportunities. Transp. Sci. 2016, 50, 579-590. [CrossRef]

2. Joerss, M.; Schröder, J.; Neuhaus, F.; Klink, C.; Mann, F. Parcel Delivery: The Future of Last Mile; Technical Report September; McKinsey \& Company: New York, NY, USA, 2016.

3. Gevaers, R.; Van de Voorde, E.; Vanelslander, T. Cost modelling and simulation of last-mile characteristics in an innovative B2C supply chain environment with implications on urban areas and cities. Procedia Soc. Behav. Sci. 2014, 125, 398-411. [CrossRef]

4. Van Duin, J.R.; Quak, H.; Muñuzuri, J. New challenges for urban consolidation centres: A case study in The Hague. Procedia Soc. Behav. Sci. 2010, 2, 6177-6188. [CrossRef]

5. Tario, J.D.; Ancar, R.; Panero, M.; Hyeon-Shic, S., Lopez, D.P. Urban Distribution Centers: A Means to Reducing Freight Vehicle Miles Traveled; Final Report; The New York State Energy Research and Development Authority: Albany, NY, USA, 2011.

6. Allen, J.; Browne, M.; Woodburn, A.; Leonardi, J. The role of urban consolidation centres in sustainable freight transport. Transp. Rev. 2012, 32, 473-490. [CrossRef]

7. Russo, F; Musolino, G.; Trecozzi, M. A system of models for the assessment of an urban distribution center in a city logistic plan. WIT Trans. Built Environ. 2013, 130, 799-810.

8. Morganti, E.; Dablanc, L.; Fortin, F. Final deliveries for online shopping: The deployment of pickup point networks in urban and suburban areas. Res. Transp. Bus. Manag. 2014, 11, 23-31. [CrossRef]

9. Song, L.; Cherrett, T.; McLeod, F; Guan, W. Addressing the last mile problem: transport impacts of collection and delivery points. Transp. Res. Rec. 2009, 2097, 9-18. [CrossRef]

10. Browne, M.; Allen, J.; Leonardi, J. Evaluating the use of an urban consolidation centre and electric vehicles in central London. IATSS Res. 2011, 35, 1-6. [CrossRef]

11. Janjevic, M.; Kaminsky, P.; Ndiaye, A.B. Downscaling the consolidation of goods-state of the art and transferability of microconsolidation initiatives. Eur. Transp. Trasp. Eur. 2013, 3, 1-23. 
12. Stodick, K.; Deckert, C. Sustainable Parcel Delivery in Urban Areas with Micro Depots. In Mobility in a Globalised World 2018; Sucky, E., Kolke, R., Biethahn, N., Werner, J., Vogelsang, M., Eds.; University of Bamberg Press: Bamberg, Germany, 2019; pp. 233-244. [CrossRef]

13. Anderluh, A.; Hemmelmayr, V.C.; Nolz, P.C. Synchronizing vans and cargo bikes in a city distribution network. Cent. Eur. J. Oper. Res. 2017, 25, 345-376. [CrossRef]

14. Verlinde, S.; Macharis, C.; Milan, L.; Kin, B. Does a mobile depot make urban deliveries faster, more sustainable and more economically viable: results of a pilot test in Brussels. Transp. Res. Procedia 2014, 4, 361-373. [CrossRef]

15. Cardenas, I.; Borbon-Galvez, Y.; Verlinden, T.; Van de Voorde, E.; Vanelslander, T.; Dewulf, W. City logistics, urban goods distribution and last mile delivery and collection. Compet. Regul. Netw. Ind. 2017, 18, 22-43. [CrossRef]

16. Olsson, J.; Hellström, D.; Pålsson, H. Framework of last mile logistics research: A systematic review of the literature. Sustainability 2019, 11, 7131. [CrossRef]

17. Bosona, T. Urban Freight Last Mile Logistics-Challenges and Opportunities to Improve Sustainability: A Literature Review. Sustainability 2020, 12, 8769. [CrossRef]

18. Perboli, G.; Tadei, R.; Vigo, D. The Two-Echelon Capacitated Vehicle Routing Problem: Models and Math-Based Heuristics. Transp. Sci. 2011, 45, 364-380. [CrossRef]

19. Lin, C.; Choy, K.L.; Ho, G.T.; Chung, S.H.; Lam, H. Survey of green vehicle routing problem: past and future trends. Expert Syst. Appl. 2014, 41, 1118-1138. [CrossRef]

20. Perboli, G.; Rosano, M. Parcel delivery in urban areas: Opportunities and threats for the mix of traditional and green business models. Transp. Res. Part C Emerg. Technol. 2019, 99, 19-36. [CrossRef]

21. Marujo, L.G.; Goes, G.V.; D’Agosto, M.A.; Ferreira, A.F.; Winkenbach, M.; Bandeira, R.A. Assessing the sustainability of mobile depots: The case of urban freight distribution in Rio de Janeiro. Transp. Res. Part D Transp. Environ. 2018, 62, 256-267. [CrossRef]

22. Conway, A.; Fatisson, P.E.; Eickemeyer, P.; Cheng, J.; Peters, D. Urban micro-consolidation and last mile goods delivery by freight-tricycle in Manhattan: Opportunities and challenges. In Proceedings of the Transportation Research Board 91st Annual Meeting, Washington, DC, USA, 22-26 January 2012.

23. Crainic, T.G.; Ricciardi, N.; Storchi, G. The-Day-Before Planning for Advanced Freight Transportation Systems in Congested Urban Areas; Université de Montréal, Centre de Recherche sur les Transports: Montreal, QC, Canada, 2005.

24. Crainic, T.G.; Ricciardi, N.; Storchi, G. Models for evaluating and planning city logistics systems. Transp. Sci. 2009, 43, 432-454. [CrossRef]

25. Gonzalez-Feliu, J.; Perboli, G.; Tadei, R.; Vigo, D. The Two-Echelon Capacitated Vehicle Routing Problem. 2008. Available online: https:/ / halshs.archives-ouvertes.fr/halshs-00879447 (accessed on 4 June 2020).

26. Quak, H.; Tavasszy, L. Customized solutions for sustainable city logistics: the viability of urban freight consolidation centres. In Transitions towards Sustainable Mobility; Springer: Berlin, Germany, 2011; pp. 213-233.

27. Van Duin, R.; Slabbekoorn, M.; Tavasszy, L.; Quak, H. Identifying dominant stakeholder perspectives on urban freight policies: A Q-analysis on urban consolidation centres in the Netherlands. Transport 2018, 33, 867-880. [CrossRef]

28. Arvidsson, N.; Pazirandeh, A. An ex ante evaluation of mobile depots in cities: A sustainability perspective. Int. J. Sustain. Transp. 2017, 11, 623-632. [CrossRef]

29. Perboli, G.; Rosano, M.; Saint-Guillain, M.; Rizzo, P. Simulation-optimisation framework for City Logistics: an application on multimodal last-mile delivery. IET Intell. Transp. Syst. 2018, 12, 262-269. [CrossRef]

30. Aljohani, K.; Thompson, R.G. A stakeholder-based evaluation of the most suitable and sustainable delivery fleet for freight consolidation policies in the inner-city area. Sustainability 2019, 11, 124.

31. Van Heeswijk, W.; Larsen, R.; Larsen, A. An urban consolidation center in the city of Copenhagen: A simulation study. Int. J. Sustain. Transp. 2019, 13, 675-691. [CrossRef]

32. Crainic, T.G.; Ricciardi, N.; Storchi, G. Advanced freight transportation systems for congested urban areas. Transp. Res. Part Emerg. Technol. 2004, 12, 119-137. [CrossRef]

33. Awasthi, A.; Chauhan, S.S.; Goyal, S.K. A multi-criteria decision making approach for location planning for urban distribution centers under uncertainty. Math. Comput. Model. 2011, 53, 98-109. [CrossRef]

34. Rao, C.; Goh, M.; Zhao, Y.; Zheng, J. Location selection of city logistics centers under sustainability. Transp. Res. Part D Transp. Environ. 2015, 36, 29-44. [CrossRef]

35. Sopha, B.M.; Asih, A.M.S.; Pradana, F.D.; Gunawan, H.E.; Karuniawati, Y. Urban distribution center location: Combination of spatial analysis and multi-objective mixed-integer linear programming. Int. J. Eng. Bus. Manag. 2016, 8, 1847979016678371.

36. Deutsch, Y.; Golany, B. A parcel locker network as a solution to the logistics last mile problem. Int. J. Prod. Res. 2018, 56, 251-261. [CrossRef]

37. Iwan, S.; Kijewska, K.; Lemke, J. Analysis of parcel lockers' efficiency as the last mile delivery solution-the results of the research in Poland. Transp. Res. Procedia 2016, 12, 644-655. [CrossRef]

38. Van Duin, J.; Wiegmans, B.; van Arem, B.; van Amstel, Y. From home delivery to parcel lockers: A case study in Amsterdam. Transp. Res. Procedia 2020, 46, 37-44. [CrossRef]

39. Perboli, G.; Brotcorne, L.; Bruni, M.E.; Rosano, M. A new model for Last-Mile Delivery and Satellite Depots management: The impact of the on-demand economy. Transp. Res. Part Logist. Transp. Rev. 2021, 145, 102184. [CrossRef]

40. Oosterom, J. The SMART Delivery Challenge; Unpublished work; Studio IlluStek: Breda, The Netherlands, 2020. 
41. Eurostat. Urban Europe-Statistics on Cities, Towns and Suburbs; Publications Office of the European Union: Luxembourg, 2016; pp. 3-69. [CrossRef]

42. European Commission. The European Green Deal; European Commission: Brussels, Belgium, 2019. Available online: https://eurlex.europa.eu/legal-content/EN/TXT/?qid=1596443911913\&uri=CELEX:52019DC0640\#document2 (accessed on 4 June 2020).

43. Durand, P. On a Longer Lifetime for Products: Benefits for Consumers and Companies; Technical Report 47; European Parliment: Strasbourg, France, 2017. [CrossRef]

44. European Commission. Circular Economy Action Plan; European Commission: Brussels, Belgium, 2020. Available online: https:/ / ec.europa.eu/environment/circular-economy/pdf/new_circular_economy_action_plan.pdf (accessed on 4 June 2020).

45. Monier, V.; Hestin, M.; Cayé, J.; Laureysens, A.; Watkins, E.; Reisinger, H.; Porsch, L; Development of Guidance on Extended Producer Responsibility (EPR). BIO Intelligence Service. In Collaboration with Arcadis; Ecologic Institute; Institute for European Environmental Policy (IEEP); Umweltbundesamt (UBA): Neuilly-sur-Seine, France, 2014. Available online: https: / /www.ecologic. eu/15139 (accessed on 4 June 2020).

46. Brar, G.S.; Saini, G. Milk run logistics: Literature review and directions. In Proceedings of the World Congress on Engineering 2011, WCE 2011, London, UK, 6-8 July 2011; Volume 1, pp. 797-801.

47. European Parliament. Directive 2006/66/EC of the European Parliament and the Council of 6 September 2006 on batteries and accumulators and waste batteries and accumulators and repealing Directive 91/157/EEC. Off. J. Eur. Union 2006, 58, 1-28.

48. Amazon. Amazon Day Delivery. 2020. Available online: https:/ /www.amazon.com/b?ie=UTF8\&language=en_US\&node=1792 8921011 (accessed on 4 June 2020).

49. Elkington, J. Cannibals with Forks: The Triple Bottom Line of 21st Century Business; Capstone: Oxford, UK, 1997. 